\title{
THE EFFECT OF CIGARETTE EXCISE TAXES ON SMOKING BEFORE, DURING AND AFTER PREGNANCY
}

\author{
Greg Colman \\ Michael Grossman \\ Ted Joyce
}

Working Paper 9245

http://www.nber.org/papers/w9245

\section{NATIONAL BUREAU OF ECONOMIC RESEARCH 1050 Massachusetts Avenue \\ Cambridge, MA 02138}

October 2002

The views expressed herein are those of the authors and not necessarily those of the National Bureau of Economic Research.

(C) 2002 by Greg Colman, Michael Grossman and Ted Joyce. All rights reserved. Short sections of text, not to exceed two paragraphs, may be quoted without explicit permission provided that full credit, including (C) notice, is given to the source. 
The Effect of Cigarette Excise Taxes on Smoking Before, During and After Pregnancy

Greg Colman, Michael Grossman and Ted Joyce

NBER Working Paper No. 9245

October 2002

JEL No. I18, H23

\section{ABSTRACT}

Recent analyses suggest that cigarette excise taxes lower prenatal smoking. It is unclear, however, whether the association between taxes and prenatal smoking represents a decline among women of reproductive age or a particular response by pregnant women. We address this question directly with an analysis of quit and relapse behavior during and after pregnancy. We find that the price elasticity of prenatal quitting and postpartum relapse is close to one in absolute value. We conclude that direct financial incentives to stop smoking during and after pregnancy should be considered.

Ted Joyce

National Bureau of Economic Research 365 Fifth Avenue, 5th Floor

New York, NY 10016

and Baruch College

ted_joyce@baruch.cuny.edu
Greg Colman

Department of Economics

Pace University

One Pace Plaza

New York, NY 10038

gcolman@pace.edu

Michael Grossman,

NBER, 365 Fifth Ave, 5th floor

New York, NY 10016

and CUNY Graduate Center

mgrossman@gc.cuny.edu 


\section{Introduction}

Prenatal smoking is the most important modifiable risk factor for poor pregnancy outcomes in the United States (U.S. Department of Health and Human Services, 1990). Approximately 20 percent of all low birth weight births are attributable to smoking, and the risk of Sudden Infant Death Syndrome (SIDS) is three times greater for women who smoke (Institute of Medicine 1985; DiFranza and Lew 1995). Nor is the impact of maternal smoking limited to the perinatal period. The American Academy of Pediatrics considers environmental tobacco smoke (ETS) a major risk factor for lower respiratory illness, middle ear effusion and asthma in children (American Academy of Pediatrics 1977).

Maternal smoking has also become an important element of the debate over the optimal level of cigarette excise taxes. Unlike the public health community, economists tend to include only the external costs of smoking - costs imposed on others - in the calculation of optimal tax levels (Manning et al. 1991; Viscusi 1995). Economists assume that parents account for or internalize the possible damage of cigarettes to the fetus or infant when deciding to smoke. ${ }^{1}$ The assumption has strong implications. Evans et al. (1999), for instance, find that if considered external, the costs of maternal smoking adds between 42-72 cents per pack to the costs of smoking in 1994 dollars. Since state and federal excise taxes averaged 75 cents in 2000 (Orzechowski and Walker 2001), the consequences of maternal smoking alone, if treated as external, would justify the present level of taxation.

Recent work by economists suggests that increases in the excise tax for cigarettes may be an effective means of lowering the prevalence of smoking among pregnant women. In two papers (Evans and Ringel 1999; Ringel \& Evans 2000), authors use national natality files and report participation elasticities of -0.5 and -0.7 , which exceed the consensus estimate of aggregate elasticities of -0.3 to -0.5 (Chaloupka and Warner 2000). Another study that also uses national natality files reports a participation elasticity of -.35 (Gruber and Köszegi 2001) The obvious advantage of national natality data is the size of the sample and its national coverage.

\footnotetext{
${ }^{1}$ The obvious exception would be the medical and remedial costs of maternal smoking borne by taxpayers.
} 
However, these studies are limited to an analysis of smoking at a single, but unspecified point during pregnancy. Consequently, it is unclear whether the prevalence of smoking during pregnancy associated with state excise taxes reflects the response to taxes by women of reproductive age, or a particular response by pregnant women (Ebrahim et al. 2000). The distinction has important implication for policy. If taxes have no effect on quit rates during pregnancy, but do lower the prevalence of smoking among women of reproductive age, then efforts to lower smoking during pregnancy might best be directed at smoking initiation among adolescent girls. Pregnancy, on the other hand, may provide important motivation for women to permanently quit. As a result, policies directed specifically at pregnant women may be more welfare enhancing than excise taxes directed at all smokers.

In this paper, we analyze the effect of cigarette excise taxes on smoking before, during and after pregnancy. With information on the prevalence of smoking at multiple points in time, we extend the literature on maternal smoking and taxes with an analysis of prenatal quit and postpartum relapse rates. We present a simple model that links quit rates to changes in smoking participation before and during pregnancy. The model provides guidance as to the presence of potential selection effects in conditional analyses based on samples of pregnant smokers. Moreover, our focus on quit probabilities provides comparisons of the effectiveness of taxes as a smoking cessation intervention to clinical trials of prenatal smoking cessation programs based on education and counseling. If taxes are associated with increased quit rates during pregnancy, then taxes may provide an important complement to other smoking cessation interventions as well as a source of funding.

Data are from the Pregnancy Risk Assessment Monitoring System (PRAMS): a random, stratified monthly survey of recent mothers overseen by the Centers for Disease Control and Prevention (CDC). We combine data from 10 states over 7 years (1993-1999) and construct a sample of 115,000 women. Although the number of states is limited, the detailed information on smoking and a richer set of covariates makes PRAMS a significant source with which to analyze the effect of cigarette taxes on maternal smoking. 


\section{Background}

The U.S. Surgeon General's 675-page report, Women and Smoking, details the distinctive hazards faced by women who smoke. "Although women and men who smoke share excess risks for diseases such as cancer, heart disease, and emphysema, women also experience unique smoking related disease risks related to pregnancy, oral contraceptive use, menstrual function and cervical cancer" (U.S. Department of Health and Human Resources 2001, p. 5). Despite the additional risks faced by women, there is only a modest literature on differences in the price sensitivity of cigarettes by gender. Farrelly and Bray (1998) use available panels from the National Health Interview Survey of individuals 18 years and older between 1976-1993 and obtain an overall elasticity of -0.26 for men and -0.19 for women. Participation elasticities are less: -0.18 and -0.09 for men and women, respectively. Lewit and Coate (1982) find participation elasticities between -0.13 and -0.39 for women 20 to 35 years of age, neither of which is statistically significant. The comparable elasticities for men range from -0.29 to -1.28 . Chaloupka and Pacula (1998) report smoking participation elasticities of -0.59 for women and -0.93 for men. All three studies use cross-state variation in prices to estimate elasticities. Thus they assume that the unmeasured factors that influence smoking in West Virginia are the same as in Maine. This leaves the studies vulnerable to significant omitted variable bias. Nevertheless, a consistent finding is that women are less sensitive to taxes than are men.

Studies of the effect of cigarettes taxes on prenatal smoking are quite recent. Evans and Ringel (1999) are the first to exploit the smoking indicator that was added to national natality files in 1989. With over 10 million births they estimate participation elasticities and conditional demand elasticities for women who gave birth between 1989 and 1992. They include a full set of state and month fixed effects and thus rely on within-state-and-month variation to identify effects of taxation. They find that a 10 percent increase in cigarette excise taxes lowers smoking participation by 5 percent, but has no effect of the number of cigarettes smoked. Their estimates are unaffected by adjustments for border crossing or clean indoor air laws. In a more recent version with this design, Ringel and Evans (2001) add three more years of natality data in order to explore the heterogeneity of responsiveness to taxes by pregnant women. 
In this analysis they report a participation elasticity of -0.7 , which the authors note is several times greater than the participation elasticity for the general population. Moreover, the absolute value of the elasticity increases with socio-economic status. Women who are married, older, and more educated have elasticities that generally exceed one. As before, taxes have no effect on the number of cigarettes smoked during pregnancy.

Evans and Ringel's elasticities have important policy implications. If pregnant women are more sensitive to changes in prices than non-pregnant women, then other financial incentives in addition to taxes could achieve significant declines. For instance, health insurance premiums could be raised for women who continue to smoke during pregnancy or bonuses awarded for women who quit.

However, other evidence suggests that Evans and Ringel's estimates are optimistic. Real cigarette prices have risen 60 percent since 1997. Given an elasticity of -0.7 , we could expect a 42 percent drop in maternal smoking. In fact, the proportion of women who smoke during pregnancy has fallen from 13.2 in 1997 to 12.2 percent in 2000, a 7.6 percent decline. Clearly, other factors besides price affect prenatal smoking. Gruber and Köszegi (2001) also use natality data and obtain an overall elasticity of -0.35 , which implies an even lower participation elasticity. Beside the extra year of data, Gruber and Köszegi aggregate births into monthly cells, which may explain differences with Ringel and Evans (2001).

The other surprising result obtained by Ringel and Evans (2001) is the positive relationship between the absolute value of the elasticities and socio-economic status. For instance, the elasticity of participation is -3.39 for college educated pregnant women and -0.49 for women with a high school degree. Part of the discrepancy is attributable to the low prevalence of smoking among college-educated women and its effect on the elasticity computation. However, even the marginal effects of taxes on smoking (in absolute value) are greater for the highly educated. This finding is counter to the result that low-income smokers are more sensitive to the price of cigarettes than higher income smokers (Farrelly and Bray 1998; Evans et al. 1999). 
The study by Gruber and Köszegi (2001) merits note because the authors find that pregnant women are forward looking in their smoking behavior. Excise taxes that have been enacted, but not yet in effect reduce smoking among pregnant women. The elasticity of cigarette consumption with respect to prices is -0.15 .

Another recent study uses longitudinal data from the National Maternal and Infant Health Survey to examine the relationship between cigarette prices and maternal smoking (Bradford 2002). Women who gave birth in 1988 are surveyed again in 1991. Since some women have had an additional child or have become pregnant at the time of the 1991 interview, the author is able to analyze the effect of pregnancy on smoking and the interaction of pregnancy and prices. He finds that the price elasticity of smoking is almost identical for both pregnant and recently pregnant women at about -0.30 . The most significant limitation to this analysis is the lack of controls for national trends. Real cigarette prices rose between 1987 and 1991 while smoking prevalence declined. In an earlier draft, the author acknowledged that dummy variables for time wipe out the effect of price. With approximately 6,000 women at four points in time in the sample, there may be insufficient within-state variation in prices to identify price effects.

In summary, the literature on the effect of cigarette taxes on smoking by women of reproductive age is remarkably sparse. There is consistent evidence that pregnant and non-pregnant women are sensitive to cigarette prices and taxes. Nevertheless, several important questions remain. First, do pregnant and non-pregnant women respond differently to taxes? The relatively large elasticities obtained by Evans and Ringel imply an interaction between pregnancy and taxes in a model of smoking participation. Ebrahim et al. (2000) question such interactions. They show that the ratio of smoking prevalence between pregnant to non-pregnant women is stable between 1987 and 1996, which they interpret as a decline in ever-smoking among women of reproductive age. We can address this question more directly by analyzing the association between taxes and quit rates during pregnancy. If the elasticity of smoking participation before and during pregnancy is the same, then taxes will have no effect on quit rates. 
We can also follow up on Gruber and Köszegi (2001) and offer some insight as to forwardlooking behavior among women who are about to become pregnant. PRAMS has information on whether the pregnancy is intended or unintended. We also know whether women who were ever smokers have stopped smoking three months before pregnancy. Many women consider the risk to the fetus as the most important reason to quit. In addition, smoking lowers the probability of conception. Thus, we expect that women who are trying to become pregnant are more likely to stop smoking in anticipation of these costs than women whose pregnancies are unintended.

Finally, we can test whether taxes are associated with post-partum relapse rates. Approximately 40 percent of women quit smoking upon the realization that they are pregnant. Such behavior underscores the importance of fetal damage as a "cost" of smoking. The fact that about approximately 75 percent of women who quit smoking during pregnancy relapse within one year of delivery suggests that these costs are viewed as largely temporary, or at least greater than the costs of second hand smoke on the newborn. Consequently, taxes as a proportion of the total costs of smoking are probably greater in the post-partum than the prenatal period and may have a greater impact on smoking. The analysis of taxes and post-partum relapse rates represents a novel contribution of this analysis.

\section{Analytical Framework}

\section{The reservation price of smoking}

We develop a simple model to study cigarette consumption decisions made by women in each of three periods surrounding pregnancy: the period before (b), the period during (d), and the period after (a). In each period $(p=b, d, a)$, her current period utility function $(U)$ depends on the number of cigarettes smoked $\left(\mathrm{C}_{\mathrm{p}}\right)$ and another good $\left(\mathrm{X}_{\mathrm{p}}\right)$ and is quadratic in these two goods:

$$
\mathrm{U}=\alpha_{\mathrm{x}} \mathrm{X}_{\mathrm{p}}-(1 / 2) \alpha_{\mathrm{xx}} \mathrm{X}_{\mathrm{p}}^{2}+\alpha_{\mathrm{c}} \mathrm{C}_{\mathrm{p}}-(1 / 2) \alpha_{\mathrm{cc}} \mathrm{C}_{\mathrm{p}}^{2}-\beta_{\mathrm{b}} \mathrm{Z}_{\mathrm{b}} \mathrm{C}_{\mathrm{b}}-\beta_{\mathrm{d}} \mathrm{Z}_{\mathrm{d}} \mathrm{C}_{\mathrm{d}}-\beta_{\mathrm{a}} \mathrm{Z}_{\mathrm{a}} \mathrm{C}_{\mathrm{a}}
$$

The parameters $\alpha_{\mathrm{x}}, \alpha_{\mathrm{xx}}, \alpha_{\mathrm{c}}, \alpha_{\mathrm{cc}}, \beta_{\mathrm{b}}, \beta_{\mathrm{d}}$, and $\beta_{\mathrm{a}}$ are positive. The variables $\mathrm{Z}_{\mathrm{b}}, \mathrm{Z}_{\mathrm{d}}$, and $\mathrm{Z}_{\mathrm{a}}$ are dichotomous indicators that equal one in the periods before, during, and after pregnancy, respectively. Hence $\beta_{d} C_{d}$ represents the cost in utility terms imposed on her fetus by a pregnant woman who smokes during 
pregnancy and $\beta_{\mathrm{a}} \mathrm{c}_{\mathrm{a}}$ represents the cost in utility terms imposed on her child by a mother who smokes after pregnancy. We assume $\beta_{\mathrm{b}}<\beta_{\mathrm{a}}<\beta_{\mathrm{d}}$. This guarantees that some women will quit smoking during pregnancy and also guarantees that not all quitters will restart.

Let $T_{p}$ be the price of a pack of cigarettes, let $\mu$ be the marginal utility of wealth, and let the market rate of interest equal the rate of time preference for the present. Then a woman will not smoke in the period before pregnancy if the monetary value of the marginal utility of cigarettes evaluated at $\mathrm{C}=0$ $\left.\left[\left(\alpha_{c} / \mu\right)-\beta_{b} / \mu\right)\right]$-termed her 'reservation price'-is smaller than or equal to $T_{b}$, and she will smoke if her reservation price exceeds $T_{b}$. In symbols

$$
\begin{aligned}
& C_{b}=0 \text { if }\left(\alpha_{c} / \mu\right)-\left(\beta_{b} / \mu\right) \leq T_{b} \\
& C_{b}>0 \text { if }\left(\alpha_{c} / \mu\right)-\left(\beta_{b} / \mu\right)>T_{b} .
\end{aligned}
$$

During the pregnancy period (d), condition (2) becomes

$$
\begin{aligned}
& C_{d}=0 \text { if }\left(\alpha_{d} / \mu\right)-\left(\beta_{d} / \mu\right) \leq T_{d} \\
& C_{d}>0 \text { if }\left(\alpha_{d} / \mu\right)-\left(\beta_{d} / \mu\right)>T_{d} .
\end{aligned}
$$

According to equation (3), with the money price of a pack of cigarettes held constant, a woman is less likely to smoke when she is pregnant than when she is not pregnant because her reservation price-the maximum price at which she is willing to become a consumer of cigarettes-falls from $\alpha_{d} / \mu-\beta_{b} / \mu$ to $\alpha_{c} / \mu$ $-\beta_{\mathrm{d}} / \mu$.

This simple framework generates demand functions for smoking participation and for the number of cigarettes smoked conditional on positive consumption. Price is expected to have a negative effect on each outcome, and both should fall during the pregnancy period. However, we are interested in the effect of cigarette excise taxes on the decision to quit smoking during pregnancy and to restart after delivery. The framework we have presented highlights that, as a first approximation, the decision to stop smoking or for that matter to stop consuming any good depends on changes in the reservation and money prices of that good between two consecutive periods rather than on the absolute levels of these prices. In particular, a reduction in the reservation price of cigarette smoking between periods $t$ and $t+1$ or an increase in the money price of cigarettes between these two periods will cause some people to quit 
smoking. The quit rate in period $t+1$ should, however, be zero if these two variables remain the same. But we know from the clinical literature that between 30 to 40 percent of smokers quit when they become pregnant (Quinn, Mullen, and Ershoff 1991). This points to a decrease in the reservation price of smoking caused by an increase in the health costs of this behavior $\left(\beta_{\mathrm{d}} / \mu\right.$ exceeds $\beta_{\mathrm{b}} / \mu$ in our notation), since rarely is there a change in the price of cigarettes in the brief period from before pregnancy to the realization of conception. The question, therefore, is what role does the level of the price play, if any, in the decision to quit smoking during pregnancy? Put differently, why might high-tax states have higher quit rates than low-tax states?

\section{Relationship between smoking participation and quitting}

The quit probability can be viewed as a conditional participation equation with implications for the elasticity of smoking participation before and during pregnancy. To illustrate, let $\Pi$ be the probability of continuing to smoke in the pregnancy period and note that $\Pi$ is equal to $1-\mathrm{Q}$, where $\mathrm{Q}$ is the quit rate. As an identity,

$$
\Pi=\frac{\mathrm{S}_{\mathrm{d}}}{\mathrm{S}_{\mathrm{b}}}
$$

where $S_{d}$ is the probability of smoking during pregnancy or the smoking participation rate during this period at the aggregate level and $\mathrm{S}_{\mathrm{b}}$ is the smoking participation rate in the period prior to pregnancy. ${ }^{2}$ The smoking participation rate in each period is negatively related to the "full price" of cigarettes in that period. The latter price is defined as

$$
F_{p}(p=b, d)=T_{p}+\left(\beta_{p} / \mu\right)=T_{p}+M_{p}
$$

${ }^{2}$ Let $\mathrm{N}_{\mathrm{b}}$ be the number of smokers before pregnancy and let $\mathrm{N}_{\mathrm{d}}$ be the number of smokers during pregnancy. Assume nobody starts smoking or resumes smoking after getting pregnant. Then $\mathrm{N}_{\mathrm{d}}=\mathrm{N}_{\mathrm{b}}-\mathrm{Q}$, where $\mathrm{Q}$ is the number of women who quit. Let $\mathrm{N}$ be the total number of women. Then

$$
\frac{\mathrm{N}_{\mathrm{d}}}{\mathrm{N}}=\frac{\mathrm{N}_{\mathrm{b}}}{\mathrm{N}}-\frac{\mathrm{Q}}{\mathrm{N}_{\mathrm{b}}} \frac{\mathrm{N}_{\mathrm{b}}}{\mathrm{N}} .
$$

Rewrite this as $S_{d}=S_{b}(1-Q)$ or $S_{d}=S_{b} \Pi$. 
where $\mathrm{M}_{\mathrm{p}}$ is the monetary value of the utility or health cost of smoking in period $\mathrm{p}$. Note that from now on, $\mathrm{M}_{\mathrm{p}}$ is added to the money price rather than subtracted from the reservation price.

Suppose that $T_{b}$ is equal to $T_{d}$. Differentiate equation (5) with respect to the common value $T$ and convert all terms to elasticities to obtain

$$
\rho=\eta_{d}-\eta_{b}
$$

According to equation (7), the elasticity of the probability of continuing to smoke during pregnancy with respect to money price $(\rho)$ is negative if the elasticity of smoking participation during pregnancy with respect to money price $\left(\eta_{\mathrm{d}}\right)$ is larger in absolute value than the elasticity of smoking participation with respect to money price before becoming pregnant $\left(\eta_{\mathrm{b}}\right){ }^{3}$ The reverse holds if $\eta_{\mathrm{b}}$ is larger than $\eta_{\mathrm{d}}$. A zero elasticity for the probability of smoking continuation implies that taxes have no differential effect on pregnant women. This would support the contention that the decline in smoking participation during pregnancy reflects the general decline among women of reproductive age (Ebrahim et al. 2000).

Let $\varepsilon_{\mathrm{p}}$ be the elasticity of smoking participation with respect to the full price and let $\mathrm{K}_{\mathrm{p}}$ be the share of money price in full price. Then

$$
\rho=K_{d} \varepsilon_{d}-K_{b} \varepsilon_{b}
$$

Clearly $\mathrm{K}_{\mathrm{d}}$ is smaller than $\mathrm{K}_{\mathrm{b}}$ since the health cost of smoking is greater in the period during pregnancy than in the period before it. Hence, if the full price elasticity were the same in each period, one obtains the somewhat counterintuitive result that an increase in the money price of cigarettes raises the probability of continuing to smoke during the pregnancy period or lowers the probability of quitting. The full price elasticity is unlikely, however, to be constant because this implies that the probability of

\footnotetext{
${ }^{3}$ The money price elasticity of smoking participation in period $\mathrm{i}$ is defined to be negative:

$$
\eta_{i}=\frac{\partial \ln S_{i}}{\partial \ln T}
$$
}

Note that the elasticity of $Q$ with respect to $T(\varphi)$ is given by 
smoking is specified as a log-linear function. This specification does not take account of the distribution of reservation prices and does not constrain the participation probability to fall between zero and one.

Suppose that the reservation price has a uniform distribution with a minimum value of $\delta$ and a maximum value of $\gamma$. Then it is easy to show that the probability of smoking in period $p$ is

$$
S_{p}=\left(\gamma-T-M_{p}\right) /(\gamma-\delta)
$$

and the elasticity of $S_{p}$ with respect to $T$ is

$$
\eta_{p}=-T /\left(\gamma-T-M_{p}\right)
$$

Clearly $\eta_{d}$ is larger in absolute value than $\eta_{b}$ since $M_{d}$ exceeds $M_{b}$. From equation (7), the elasticity of the probability of continuing to smoke during pregnancy with respect to T $(\rho)$ is negative, and the elasticity of the quit probability with respect to $\mathrm{T}$ is positive.

Now suppose that the reservation price has a normal distribution so that the probability of smoking can be specified as a probit function. This specification constraints $S_{i}$ to lie between zero and one both theoretically and empirically. Let $\phi_{\mathrm{p}}$ be the probit coefficient of money price in each period.

Then

$$
\rho=\mathrm{T}\left(\phi_{\mathrm{d}} \lambda_{\mathrm{d}}-\phi_{\mathrm{b}} \lambda_{\mathrm{b}}\right)
$$

where $\lambda_{\mathrm{p}}$ is the inverse of the Mills ratio. Since $\lambda_{\mathrm{p}}$ is negatively related to the probability of smoking and since women are less likely to smoke in the pregnancy period, $\lambda_{d}$ exceeds $\lambda_{b}$. Thus, $\rho$ is negative if $\phi_{d}$ equals $\phi_{\mathrm{b}}$ and could be negative even if $\phi_{\mathrm{d}}$ is smaller in absolute value than $\phi_{\mathrm{b}}$. Moreover, given the strong possibility of lagged as opposed to instantaneous adjustment, $\phi_{\mathrm{d}}$ might well exceed $\phi_{\mathrm{b}}$.

\section{Potential selection effects}

A final consideration is that reservation prices before and during pregnancy are not observed and must be replaced by their determinants. One of these determinants is the unobserved propensity or taste for smoking. Denote this propensity by $\mathrm{V}_{\mathrm{Q}}$ and define it such that an increase in $\mathrm{V}_{\mathrm{Q}}$ causes an increase in the quit probability. Note that this disturbance term surely is negatively correlated with the disturbance

$$
\varphi=-\rho \frac{\Pi}{1-\Pi}=\left(\eta_{b}-\eta_{d}\right)\left(\frac{\Pi}{1-\Pi}\right)
$$


term in the equation for smoking participation before pregnancy $\left(\mathrm{V}_{\mathrm{S}^{*}}\right)$, where $\mathrm{S}^{*}$ is a latent variable governing the propensity to smoke before pregnancy, and an increase in $\mathrm{V}_{\mathrm{S}^{*}}$ causes $\mathrm{S}^{*}$ to rise. In a sample of women who smoked prior to pregnancy, a woman from a high price state is likely to have a high value of $\mathrm{V}_{\mathrm{S}^{*}}$. Hence $\mathrm{T}_{\mathrm{b}}$ and $\mathrm{V}_{\mathrm{S}^{*}}$ are positively correlated in the quit sample (and $\mathrm{T}_{\mathrm{b}}$ and $\mathrm{V}_{\mathrm{Q}}$ are negatively correlated) even if they are uncorrelated in the population at large.

The positive association between $T_{b}$ and $V_{S^{*}}$ will bias downward the effect of taxes on quit rates. However, we can obtain insight as to the importance of such selection effects by comparing estimates of the price elasticity of quitting during pregnancy estimated directly to the same elasticity obtained from the participation equations. Specifically, we will estimate smoking participation equations before and during pregnancy as a function of $\mathrm{T}_{\mathrm{b}}$. Provided taxes are exogenous, we can back out an unbiased estimate of the quit elasticity (see footnote 3). We can compare this estimate to the one obtained directly by regressing the probability of quitting during pregnancy on $\mathrm{T}_{\mathrm{b}}$. If the estimate from the direct estimation is substantially less than the estimate obtained from the unconditional participation equations, then we would have evidence of selection effects. ${ }^{4}$

To summarize, we have outlined a framework in which the conditional probability of quitting during pregnancy may be positively related to cigarette taxes. If true, then we should find that the elasticity of smoking participation during pregnancy exceeds in absolute value the elasticity of smoking participation before pregnancy. This would be consistent with recent work based on natality data in which the elasticity of smoking participation during pregnancy appears substantially greater than the elasticity of participation among women of reproductive age (Evans and Ringel 1999; Ringel and Evans 2001). Two caveats exists. First, changes in the non-monetary price of smoking associated with childbearing can yield negative quit elasticities (equation 8). Second, a larger proportion of women who

\footnotetext{
${ }^{4}$ One way to account for the bias just outlined is to fit a bivariate probit model with sample selection (Wynand and van Praag 1981; Greene 2000). We experimented with such models but identification proved difficult. We used taxes at age 14 to predict smoking participation just prior to pregnancy. However, taxes at 14 had limited explanatory power. One reason is that we did not know the mother's state of residence at birth or more importantly, at age 14. This form of measurement error would tend to bias out estimates downwards.
} 
smoke just prior to pregnancy in high-tax states are likely to have a stronger preference for smoking than their counterparts in low-tax states. As a result, the elasticity of quitting with respect to the monetary may be biased downwards in a sample of pregnant smokers.

\section{Empirical Implementation}

\section{Data}

The Pregnancy Risk Assessment Monitoring System (PRAMS) is a random, stratified monthly survey of recent mothers selected from birth certificates. PRAMS was initiated by the Centers for Disease Control in 1987 as a response to the slowdown in the rate of decline in infant mortality and the absence of any decline in the rate of low birth weight births. PRAMS surveys are carried out by participating states following explicit guidelines developed by the CDC. Each month the PRAMS staff in each state selects between 100 and 250 recent mothers from birth certificates by stratified systematic sampling with a random start. Stratification variables, such as birth weight and race or ethnicity, vary among states. All states over-sample women at increased risk for adverse pregnancy outcomes. Sampled mothers are then sent a self-administered questionnaire two to six months after delivery; non-respondents are followed up by telephone. Response rates average between 70 and 80 percent after follow up. (See http://www.cdc.gov/nccdphp/drh/methodology.htm for more details.)

Twenty-five states participated in PRAMS in 2000 up from five states in 1988. We use surveys from 10 states that participated for at least 5 of the six years between 1993 and 1999: Alabama, Alaska, Florida, Georgia (1993-1997), Maine, New York State (excluding New York City) Oklahoma, South Carolina, Washington and West Virginia. There are 115,000 observations, a total that, when weighted, represents approximately 4,605,470 births, or 17 percent of deliveries in the U.S. over the same period.

The questionnaire in PRAMS asks women if they ever smoked at least 100 cigarettes in their entire life. Those that answer 'yes' are asked to record the number of cigarettes or packs of 20 cigarettes they smoked per day, on average, in the three months before they were pregnant. They may also respond by indicating that they smoked less than one cigarette per day, that they didn't smoke at all, or that they 
do not know. The same set of questions are asked about the period three months before delivery and at the time of the survey, which occurs between 2 and 6 months after delivery.

We are primarily interested in the change in smoking behavior. ${ }^{5}$ We create four dichotomous indicators of change. The first is one if the woman ever-smoked but did not smoke three months before pregnancy (Quit_ever_before). The second is one if the woman smoked three months before pregnancy but not three months before delivery (Quit_before_during). The third indicator is one if the woman stopped during pregnancy, but resumed between 2 to 6 months postpartum (Resume). And the final indicator is one if the woman smoked before but not postpartum (Quit_before_after). We refer to these women as "permanent" quitters. The importance of permanent quits is that women who stop smoking during pregnancy, but resume postpartum, are still at double the risk for SIDS (Schoendorf and Kiley 1992).

We do not analyze smoking intensity with PRAMS, but we do control for pre-pregnancy cigarette consumption in the Quit_before_during, Resume, and Quit_before_after equations. Consumption before pregnancy is a measure of the stock of smoking capital (Becker, Grossman and Murphy 1994). The clinical literature indicates that the lightest smokers prior to pregnancy are the most likely to quit during and least likely to resume (Li et al. 1993; Quinn, Mullen, and Ershoff 1991; Fingerhut, Kleinman and Kendrick 1990). We create a trichotomous indicator of pre-pregnancy consumption: less than 10 cigarettes per day, between 10 and 20 cigarettes per day and more than 20 per day. We eliminated women who did not know how much they smoked before pregnancy $(n=4325)$, during pregnancy $(n=2808)$ and after delivery $(n=2381)$.

PRAMS also contains covariates in addition to those on birth certificates. These include health insurance status at delivery, family income, and pregnancy intention. We use pregnancy intention to test for forward-looking behavior. Women are asked whether at the time that they first realized that they were pregnant if they wanted to become pregnant then, or at some other time (mistimed) or not at all (unwanted). We characterize pregnancies that are mistimed or unwanted as unintended. Smoking

\footnotetext{
${ }^{5}$ We analyze smoking participation three months before delivery in order to compare PRAMS to published works.
} 
imposes two potential costs on women who want to have children. First, smoking inhibits conception. Second, and more well known, is the risk of adverse birth outcomes (U.S. Department of Health and Human Resources 2001). Thus, women who are trying to become pregnant may be more likely to quit in the three months before pregnancy due to these anticipated costs, than women whose pregnancies are unintended.

\section{Reported Smoking}

A limitation of self-reported smoking is the potential for underreporting. Clinical studies or prenatal smoking that use biological markers to estimate exposure find that a little as 10 and as much as 30 percent of prenatal smoking is not reported by the women. Birth certificates capture less smoking than hospital medical charts (Piper et al. 1993; Buescher et al. 1993) and the prevalence of smoking as reported in PRAMS exceeds that reported on birth certificates. The latter is likely an underestimate of the true difference between birth certificates and PRAMS since birth certificates ask about smoking at any time during pregnancy and PRAMS specifically asks about smoking in the three months before delivery. If smoking were equally well reported on PRAMS and birth certificates, the percentage of women reporting smoking anytime during pregnancy should exceed the percentage reporting smoking during the last trimester, since the latter group is a subset of the former. For example, in the National Household Survey on Drug Abuse, 20 percent of women reported smoking at any time during pregnancy, but only 16 percent reported smoking during the last trimester.

Figure 1 compares smoking during pregnancy from three sources: the Behavioral Risk Factor Surveillance System (BRFSS), PRAMS and birth certificates. ${ }^{6}$ Women in the BRFSS are asked about smoking and later asked whether they are pregnant at this time. If we accept that there are few false positives, then PRAMS is superior to birth certificates and the BRFSS as a screen for smoking. Smoking in the last three months of pregnancy is between 1 and 2 percentage points higher than what is recorded

\footnotetext{
${ }^{6}$ The BRFSS is a monthly telephone survey of adult health practices and behaviors by the Centers for Disease Control and Prevention and State health departments. Initiated in the early 1980's, the BRFSS interviews approximately 125 adults per month in each state (Remington et al. 1988). Fifty states now participate. We use data from 1987 to 2000 . There are 33 states in 1987, a number which rises to 50 by 1993 . We limit the sample to women 18 to 44 years of age.
} 
for smoking during pregnancy on birth certificates. Also noteworthy is that the prevalence of smoking based on birth certificates is similar in nine of the 10 PRAMS states to all available states. ${ }^{7}$

\section{Econometric model}

We use probits to estimate smoking participation and quit models. The basic specification is as follows:

$$
\operatorname{Pr} o b\left(S_{i j t}=1\right)=\Phi\left(\sum_{k} \sigma_{k} X_{k i j t}+\phi T+\tau_{j}+\tau_{t}+e_{i j t}\right)
$$

where $S_{\mathrm{ijt}}$ is one if woman $\mathrm{i}$, in state $\mathrm{j}$, and year $\mathrm{t}$ smokes. Let $\mathrm{X}_{\mathrm{kijt}}$ be maternal characteristics, $\mathrm{T}$ is the level of state and federal taxes in 1982-84 dollars, $t_{j}$ and $t_{t}$ are state and year fixed effects respectively, and $\mathrm{e}_{\mathrm{ijt}}$ is the residual. All analyses are weighted with the survey weights and we use robust procedures for the standard errors that cluster on state and year.

\section{Results}

\section{Smoking participation}

We first use PRAMS to analyze the effect of state cigarette excise taxes on smoking participation before, during and after pregnancy. Results are shown in Table 1. For each outcome in, we present separate regressions for a contemporaneous tax and taxes lagged approximately nine months. ${ }^{8}$ Estimates should be interpreted as the marginal change in probability of each outcome given a one cent change in the real tax. We also present price elasticities for each outcome under the assumption that a one cent increase in taxes causes a commensurate increase in price (Evans et al. 1999).

Taxes are negatively related to smoking before, during and after pregnancy. Of the six estimates, five have t-ratios greater than one, although only two are statistically significant at conventional levels $(\mathrm{p}<.05)$. Implied price elasticities range from -0.23 to $-0.91 .^{9}$ The largest elasticity pertains to taxes three months before pregnancy on smoking participation three months before delivery. For two of the three

\footnotetext{
${ }_{8}^{7}$ New York, one of the 10 PRAMS states, did not report smoking on the birth certificate.

${ }^{8}$ The decision to lag nine approximately nine months exploits the space between reporting period. Thus, women are asked about smoking three months before delivery as well as three months before pregnancy, a spacing of nine months. Similarly, women are asked between 2 and 6 months postpartum, upwards of nine months after they were asked about smoking before delivery.
} 
outcomes, the lagged exceed the contemporaneous estimate. The weakest association is the relationship between taxes three months before delivery and smoking participation also three months before delivery (column 3). This is not surprising given that the vast majority of women quit early in pregnancy

(Fingerhut, Kleinman and Kendrick 1990). Women who smoke in the last trimester are likely to have the strongest preference for smoking and thus, the least sensitive to changes in monetary prices.

\section{Quit and relapse behavior}

As we argued above, pregnancy causes a large decrease in the reservation price of smoking due to the risks it poses for the fetus. Thus, even if taxes and prices remained unchanged, we expect between 30 and 40 percent of women who smoke prior to pregnancy to quit during pregnancy. The question we address in this section is whether states with high taxes have higher quit rates and lower relapse rates than states with lower taxes.

Figures 2 through 5 display four outcomes related to changes in smoking behavior around the time of birth. In each Figure, we show separate series for New York and Washington, Alaska and Maine and the other six states in PRAMS. The grouping is based on changes in state excise taxes. New York and Washington raised taxes between 1993 and 1995; Alaska and Maine raised taxes one month apart in 1997. The other six states did not increase state excise taxes over this time period. ${ }^{10}$

There is no apparent association between state excise taxes and quit rates three months before pregnancy among ever smokers (Figure 2). Quit rates during pregnancy rise sharply after 1994 in New York and Washington and are relatively flat in the other states between 1993 and 1996 (Figure 3); and although there is an increase in quit rates in Alaska and Maine after 1996, it is difficult to distinguish the rise from the upward trend in quit rates in the non-tax-changing states (Figure 3). There is no obvious association between the rate of postpartum relapse and the timing of the state tax changes. Nevertheless, relapse rates are similar in 1993 among all states but noticeably less among the tax-changing states in 1999 (Figure 4). Finally, permanent quit rates defined as the percent of women who smoked before

\footnotetext{
${ }^{9}$ We assume that a one cent increase in taxes increase price by the same amount.

${ }^{10}$ Federal tax increases bracket our study period. The federal excise tax increased from 20 to 24 cents in January, 1993 and from 24 to 32 cents in January, 2000.
} 
pregnancy but who do not smoke postpartum jumped sharply in New York and Washington after 1995 (Figure 5). In short, there is some visual evidence that smoking behavior changed in the wake of state excise tax increases, but the strength of the association is not apparent. We turn, therefore, to the regressions of quit behavior.

Table 2 shows the means for the covariates that we use in the quit regressions stratified by year and tax-changing states. A salient feature is that the intensity of smoking prior to pregnancy in the two groups of states is similar in 1993. Approximately 20 percent of pregnant smokers in tax-changing and non-tax-changing states smoke less than 11 cigarettes (light smokers) and 16 percent smoked more than a pack per day (heavy smokers) in 1993. By 1999 there are more light smokers and fewer heavy smokers in the tax-changing states relative to the non-tax-changing states. There is also a noticeable shift in the age distribution of pre-pregnancy smokers. The proportion of teens among pre-pregnant smokers increases from 12 to 18 percent between 1993 and 1999 in the tax-changing states and from 16 to 19 percent in the non-tax-changing states. The shift in age may explain in part the relative increase in light smoking. We turn therefore, to the multivariate estimates in order to adjust for the changing characteristics of pre-pregnant smokers in the quit models.

The probit regressions pertain to the four quit probabilities shown in Figures 2 through 5 . We associate taxes at the beginning of each quit period with quitting behavior. Thus, we use taxes at age 14 in the equation of ever smokers who no longer smoke three months prior to conception (Quit_ever_before); similarly, we use taxes three months before conception in the quit equations during pregnancy (Quit_before_during) and permanent quits (Quit_before_after) and taxes three months before delivery in the relapse models. Results are displayed in Table 3. Taxes at age 14 are strongly and positively correlated with quitting prior to pregnancy. The elasticity is 0.66 (column 1). Taxes before pregnancy significantly increase the likelihood that a woman will quit before delivery (column 2). The implied price elasticity is 1.04 . Taxes are also associated with a lower probability that a woman will resume smoking between 2 to 6 months postpartum, although the estimate is not is not statistically significant (column 3). The last estimate associates taxes with what we call "permanent" quits: women 
who smoked before pregnancy but not after. Permanent quits include women who smoked during pregnancy and stopped postpartum, although this represents only 10 percent of "permanent" quitters.

The responsiveness of prenatal smokers to taxes is large enough to account for a substantial portion of the rise in quit rates in recent years. From 1993 to 1999 among PRAMS states, the quit rate during pregnancy rose from 37.3 to 46.4 percent and the weighted average tax rose from $\$ 0.33$ to $\$ 0.40$. The coefficient on tax in column 2 implies that quit rates would have risen by approximately 2.5 percentage points due to taxes alone, or over a quarter of the actual change. ${ }^{11}$ We obtain a similar result based on the change in prices. For instance, prices rose from $\$ 1.33$ to $\$ 1.41(6.1 \%)$ in real 1982-84\$ from 1993 to 1999 in our PRAMS states. Given a price elasticity of 1.04, we would expect the quit rate to rise to $39.6 \%$, which again is approximately a quarter of the observed change in quits. ${ }^{12}$

As we argued above, the quit elasticity obtained from the sample of pre-conception smokers may be biased downwards since women in high-tax states that smoke may have a greater taste for smoking. To obtain insight as to possible selection effects, we use estimates from the participation equations in Table 1 to back out the implied quit elasticity. ${ }^{13}$ From this exercise we obtain a quit elasticity of 0.84 , which is less than the estimated elasticity, but reasonably close.

We also display the marginal effects of selected covariates in Table 3. As noted above, women who intend to become pregnant are much more likely to quit smoking prior to pregnancy, than women whose pregnancies are unintended. Once conception is known, however, there is no difference in smoking behavior by pregnancy intention. We interpret this finding as support for the importance of future "prices" on current behavior. Another notable finding is the robust impact of first births on quit behavior. Although women delivering their first child are 7 percentage points less likely to quit prior to pregnancy, once pregnant their smoking behavior changes much more than women of higher order births. Specifically, women having a first birth are 14 percentage points more likely to quit during pregnancy, 10

\footnotetext{
$112.5=.0035 *(\$ 0.40-\$ 0.33)$.

12 The price changes might appear modest. However, we use the price three months before pregnancy. Thus, many of the pregnancies in our 1999 sample were unaffected by the large price increases that followed the tobacco settlement in November of 1998. In fact, if we use the price three months before delivery, the change in 1982-84 dollars between 1993 and 1999 in our 10 PRAMS states is from $\$ 1.23$ to $\$ 1.71$ or 39 percent.
} 
percentage points less likely to resume after delivery and 10 percentage points more likely to quit permanently relative to women who deliver a higher order birth. As a percentage of the mean of each quit behavior, these effects are very large. One speculation is that women use previous birthing experience to adjust the expected costs of smoking. Even for women who smoke, the probability of a low birth weight birth is only about 0.12 , or double of those that don't. Thus, the high probability of a good birth outcome despite smoking may lead women to discount the risk of prenatal smoking. One way to test this would be to include a measure of previous adverse birth outcomes. We lacked such data in PRAMS. However, in a study of consecutive births in Georgia, researchers found that women who smoked during their first pregnancy were less likely to smoke in the second, if the first infant had died. Interestingly, a first birth of low birth weight had no effect on smoking during the second pregnancy (Dietz et al. 1997).

The other noteworthy result pertains to prior smoking behavior among those who quit. As shown in Table 4, light smokers, those that smoke less than a half a pack a day, are much more likely to quit than heavier smokers. In our sample, for instance, 71 percent of light smokers, 36 percent of moderate smokers and 22 percent of heavy smokers quit during pregnancy.

\section{Sensitivity analysis}

One concern is that our results are sensitive to the inclusion or exclusion of a particular state, since we have only 4 states in which tax changes were enacted (Alaska, Maine, New York and Washington). In Table 4 we present additional estimates of the marginal effect of taxes on the probability of quitting during pregnancy. We focus on quits from before to during pregnancy given the health consequences of quitting and the robustness of our initial findings. Each row is from a separate regression in which we have altered the specification or the sample. Row 1 repeats the estimate from Table 3 for convenience. The specification in row 2 includes no covariates other than state and year fixed effects. In rows 3 through 6 we drop one of the tax-changing states and in rows 7 through 10 we include only one of the tax-changing states. Except for when we include New York (row 9), marginal effects range from .0020 to .0042 and are statistically significant in 7 of the 8 cases. In the last row we include

\footnotetext{
${ }^{13}$ Using the formula in footnote 8 and estimates from Table 1 , the implied quit elasticity equals $[-0.30-(-0.91)]^{*}(.58 / .42)=0.84$.
} 
only the tax-changing states. In this specification we rely on the variation in the timing of the tax increases to provide the relevant "comparison" state. The marginal effect falls by almost half when we include only the four tax-changing states. Nevertheless, changes in taxes still explain almost a quarter of the increase in quits over the study period. ${ }^{14}$

The next set of analyses explores the heterogeneity of taxes on quit probabilities by parity, maternal schooling and pre-pregnancy smoking. We consider only binary stratification because of sample size limitations. Estimates are shown in Table 5. Although none of the differences in marginal effects within each category is statistically significant, we find that the marginal effect of taxes on quit probabilities are greater among women with first births, less education and more pre-conception smoking.

\section{Conclusion}

In this paper we examine whether increasing cigarette taxes is an effective way to reduce smoking among pregnant women. One justification for raising taxes would be that they influence pregnant women more, and thus change behavior most where the externalities are greatest. We find strong support for the use of taxes in our quit equations. We estimate that a 10 percent increase in cigarette taxes would increase the probability of a woman quitting by 10 percent, a result that holds up in separate regressions stratified by education, parity, and pre-pregnancy smoking and with various combinations of states. Since higher costs of smoking appear to be quite effective in inducing women to quit smoking during pregnancy, direct financial incentives to stop smoking during and after pregnancy should be considered.

We also find that women who smoke during pregnancy are not a random cross-section of reproductive-age smokers. In particular, more women who intend to become pregnant quit prior to pregnancy than women whose pregnancy was unintended. We also find that women delivering their first child are much more likely to quit during pregnancy and less likely to resume postpartum than women

\footnotetext{
${ }^{14}$ The weighted average of real state taxes rose by 15.5 cents between 1993 and 1999 in Alaska, Maine, New York and Washington. The percent of women who quit smoking during pregnancy increased by 13.0 percentage points, from 34.3 in 1993
} 
with previous live births. Perhaps cessation policies aimed specifically at first-time mothers would persuade more women to quit than a general program aimed at all pregnant women.

One concern is that quit and relapse elasticities based on a sample of pregnant women who smoke are biased since smokers in high-tax states would have a stronger preference for cigarettes than women in low-tax states. Using the relationship between quit and participation elasticities, we show that the elasticity of quitting during pregnancy estimated directly is close to the quit elasticity that we obtain with the difference in participation elasticities before and during pregnancy. We interpret this result as some evidence that the conditional estimates based on a sample of smokers are not obviously contaminated by pre-pregnancy attrition in high-tax states.

Maine, Washington and New York have increased cigarette excise taxes by a simple average of 30.5 cents in constant dollars since 1999. Based on our estimates, quit rates should increase 5.8 percentage points in these states. ${ }^{15}$ If realized, these changes compare favorably to the change in quit rates achieved by prenatal smoking cessation programs. A meta-analysis of prenatal smoking interventions found that quit probabilities were approximately 6.6 percentage points greater for those in treatment relative to control groups (Dolan-Mullen, Ramirez and Groff 1994). The recent tax increases in New York and Washington are large and probably unrepresentative of future tax increases in most other states. Nevertheless, they underscore the potential of increasing the monetary costs of smoking during pregnancy to affect quit rates.

Taxes appear to be nearly as effective in reducing relapse rates as in encouraging quitting. We find that a 10 percent rise in taxes reduces the likelihood of resuming smoking by 10 percent. However, despite the increased taxes of recent years, half of all quitters resume smoking within six months of delivery and 75 percent resume within a year, suggesting that their reservation prices tend to return to prepregnancy levels. One interpretation is that new mothers do not perceive postpartum smoking to be as harmful as prenatal smoking despite recent research on the relationship between smoking and SIDS,

to 47.3 in 1999 . Thus, $.0019 * 15.5=0.029$ which is 22 percent of the change. We obtain a similar result if we use the quit elasticity of 0.67 and a real price change of 14 percent.

${ }^{15}$ Use the marginal effect for the tax-changing states, .0019 from Table 4, and multiply by 30.5 . 
asthma and lower respiratory infections. This suggests that doctors and public agencies need to better advertise the dangers of postpartum smoking. 


\section{Acknowledgements}

This research was supported by a grant from the National Institute for Child Health and Human Development (NICHD) to Baruch College, the City University of New York (1 R01 HD40218-01). Greg Colman also acknowledges dissertation support from The Commonwealth Fund (Grant No. 20000463). We thank Robert Kaestner, Kevin M. Murphy, and participants from the NBER Summer Institute for comments and the PRAMS Working Group and the Centers for Disease Control and Prevention (CDC) and in particular, Mary Rogers, Christopher Johnson and Nedra Whitehead for access to and technical support regarding the PRAMS survey. The views expressed in the manuscript are the authors and not those of NICHD, the Commonwealth Fund, the PRAMS Working Group, the CDC or Baruch College. 


\section{References}

American Academy of Pediatrics, Committee on Environmental Health, 1997. Environmental Tobacco Smoke: A Hazard to Children. Pediatrics 99, 639-642.

Bradford, W.D., 2002. Pregnancy and the Demand for Cigarettes. Manuscript. University of South Carolina.

Buescher, P.A., Taylor, K.P., Davis, M.H., Bowling, J.M., 1993. The Quality of the New Birth Certificate Data: A Validation Study in North Carolina. American Journal of Public Health 83, 1163-1165.

Chaloupka, F. J., Pacula, R.L, 1998. An Examination of Gender and Race Differences in Youth Smoking Responsiveness to Price and Tobacco Control Policies. National Bureau of Economic Research Working Paper no. 6541.

Chaloupka, F.J., Warner, K.E., 2000. The Economics of Smoking. In Newhouse, J.P., Culyer, A. (eds.), The Handbook of Health Economics. Elsevier Science, Amsterdam, pp. 1539-1627.

Dietz, P.M., Adama, M.M., Rochat, R.W., Mathis, M.P., 1997. Prenatal Smoking in Two Consecutive Pregnancies: Georgia, 1989-1992. Maternal and Child Health Journal, 1(1), 43-51.

DiFranza, J.R., Lew, R.A., 1995. The Effect of Maternal Cigarette Smoking on Pregnancy: Complications and Sudden Infant Death Syndrome. The Journal of Family Practice 40, 385-94.

Dolan-Mullen, P., Ramirez, G. and J.Y. Groff. 1994. "A meta-analysis of randomized trials of prenatal smoking cessation interventions." American Journal of Obstetrics and Gynecology. 171(5), 1328-1334.

Douglas, S. M., 1998. The Duration of the Smoking Habit. Economic Inquiry 36, 49-64.

Ebrahim, S.H., Floyd, R.L., Merritt, R.K., Decoufle, P., Holtzman, D., 2000. Trends in PregnancyRelated Smoking Rates in the United States, 1987-1996. Journal of the American Medical Association $283,361-366$.

Evans, W. N., Ringel J.S., Stech, D., 1999. Tobacco Taxes and Public Policy to Discourage Smoking. In J. M. Poterba (ed.), Tax Policy and the Economy. MIT Press, Cambridge, MA, Vol. 13, 1-55.

Evans, W. N., Ringel, J.S., 1999. Can Higher Cigarette Taxes Improve Birth Outcomes? Journal of Public Economics 72, 135-154.

Farrelly, M.C., Bray, J.W., 1998. Response to increases in cigarette prices by race/ethnicity, income, and age groups - United States, 1976-1993. Morbidity and Mortality Weekly Report 47(29), 605-9.

Fingerhut, L.A., Kleinman, J.C., Kendrick, J.S., 1990. Smoking Before, During, and After Pregnancy. American Journal of Public Health 80, 541-544.

Greene, W.H., 2000. Econometric Analysis, $4^{\text {th }}$ Edition. Prentice Hall, Upper Saddle River, New Jersey.

Gruber, J., Köszegi, B., 2001. Is Addiction 'Rational'? Theory and Evidence. Quarterly Journal of Economics 116(4), 1261-1305.

Institute of Medicine, 1985. Preventing Low Birthweight. Washington, D.C.: National Academy Press. 
Lewit, E. M., Coate, D., 1982. The Potential for Using Excise Taxes to Reduce Smoking. Journal of Health Economics 1, 121-45.

Li, C.Q., Windsor, R.A., Perkins, L., Goldenberg, R.L., Lowe, J.B., 1993. The Impact on Infant Birth Weight and Gestational Age of Cotinine-Validated Smoking Reduction During Pregnancy. Journal of the American Medical Association 269, 1519-1524.

Orzechowski and Walker, 2001. The Tax Burden on Tobacco. Orzechowski and Walker.

Piper, J.M., Mitchel, E.F Jr., Snowden, M., Hall, C., Adams, M., Taylor, P., 1993. Validation of 1989 Tennessee Birth Certificates Using Maternal and Newborn Hospital Records. American Journal of Epidemiology 137, 158-68.

Quinn, V.P., Mullen, P.D., Ershoff, D.H., 1991. Women Who Stop Smoking Spontaneously Prior to Prenatal Care and Predictors of Relapse Before Delivery. Addictive Behaviors 16, 29-40.

Remington, P.L., Smith, M.Y., Williamson, D.F., Anda, R.F., Gentry, E.M., Hogelin, G.C., 1988. Design, Characteristics, and Usefulness of State-Based Behavioral Risk Factor Surveillance: 1981-1987. Public Health Reports 103, 366-375.

Ringel, J., Evans, W.N., 2001. Cigarette Taxes and Smoking During Pregnancy. American Journal of Public Health 91, 1851-1856.

Schoendorf, K.C., Kiley, J.L., 1992. Relationship of Sudden Infant Death Syndrome to Maternal Smoking During and After Pregnancy. Pediatrics 90, 905-908.

U.S. Department of Health and Human Services, 1990. The Health Benefits of Smoking Cessation: A Report of the Surgeon General U.S. Department of Health and Human Services, Public Health Service, Rockville (MD).

U.S. Department of Health and Human Services, 2001. Women and Smoking: A Report of the Surgeon General. Office of the Surgeon General, U.S. Department of Health and Human Services, Public Health Service, Rockville (MD).

Viscusi, W. K., 1995. Cigarette Taxation and the Social Consequences of Smoking. Tax Policy and the Economy. 9, 51-101.

Wasserman, J., Manning, W.G., Newhouse, J.P., Winkler, J.D., 1991. The Effects Of Excise Taxes and Regulations on Cigarette Smoking. Journal of Health Economics 10, 43-64.

Wynand, P., van Praag, B., 1981. The Demand for Deductibles in Private Health Insurance: A Probit Model with Sample Selection. Journal of Econometrics 17, 229-252. 
Table 1: Smoking Participation Before, During, and After Pregnancy in PRAMS , 1993-1999

\begin{tabular}{|c|c|c|c|c|c|c|}
\hline & \multicolumn{6}{|c|}{ PRAMS } \\
\hline & \multicolumn{2}{|c|}{$\begin{array}{l}\text { Smoked three months } \\
\text { before conception }\end{array}$} & \multicolumn{2}{|c|}{$\begin{array}{l}\text { Smoked three months } \\
\text { before delivery }\end{array}$} & \multicolumn{2}{|c|}{$\begin{array}{c}\text { Smoked at interview } \\
\text { date }\end{array}$} \\
\hline & $(1)$ & $(2)$ & (3) & $(5)$ & $(6)$ & $(7)$ \\
\hline Real tax, 3 months before conception & $\begin{array}{c}-0.00063 \\
(1.28)\end{array}$ & & & $\begin{array}{l}-0.00108 * \\
(3.08)\end{array}$ & & \\
\hline Real tax, 9 months before conception & & $\begin{array}{l}-0.00070 \\
(1.57)\end{array}$ & & & & \\
\hline Real tax, 3 months before delivery & & & $\begin{array}{l}-0.00023 \\
(0.84)\end{array}$ & & & $\begin{array}{l}-0.00057 \\
(1.43)\end{array}$ \\
\hline Real tax at interview date & & & & & $\begin{array}{l}-0.00111 \\
(2.32)\end{array}$ & \\
\hline Observations & 96895 & 96895 & 100960 & 98153 & 95886 & 101259 \\
\hline Elasticity & -0.30 & -0.34 & -0.23 & -0.91 & -0.36 & -0.69 \\
\hline Mean of the dependent variable & 0.26 & 0.26 & 0.15 & .15 & 0.22 & 0.22 \\
\hline
\end{tabular}

The participation models were estimated as probits. Values are marginal effects with robust z-statistics in parentheses. All models include indicator variables for family income (5), health insurance (4) maternal education (5), age (2), race (2), marital status (1), parity (1), pregnancy intention (1) as well as state and year fixed effects. All models but column 6 also include indicator variables (5) for income. The ten PRAMS states are AL, AK, FL, GA (1993-97), ME, NY, OK, SC, WA and WV. All models are weighted by survey weights and standard errors have been adjusted for clustering by state and year. The sample based on birth certificates does not include NY. * significant at 5\% 
Table 2. Mean Characteristics of Women who Smoked Three Months before Pregnancy by Year (1993 and 1999) and Tax-Changing versus Non-Tax-Changing State:

\begin{tabular}{|c|c|c|c|c|}
\hline \multirow[b]{2}{*}{ Variable: } & \multicolumn{2}{|c|}{$\begin{array}{c}\text { Tax-Changing States: } \\
\text { AK, ME, NY, WA }\end{array}$} & \multicolumn{2}{|c|}{$\begin{array}{l}\text { Non-Tax-Changing States: } \\
\text { AL, FL, GA, OK, SC, WV }\end{array}$} \\
\hline & $\begin{array}{c}1993 \\
(\mathrm{~N}=1576)\end{array}$ & $\begin{array}{c}1999 \\
(\mathrm{~N}=1557)\end{array}$ & $\begin{array}{c}1993 \\
(\mathrm{~N}=3047)\end{array}$ & $\begin{array}{c}1999 \\
(\mathrm{~N}=2418)\end{array}$ \\
\hline $\begin{array}{l}\text { Quit during pregnancy } \\
\text { Family income (000's 1982-84\$) }\end{array}$ & 0.344 & 0.473 & 0.388 & 0.458 \\
\hline$<10$ & 0.374 & 0.381 & 0.460 & 0.334 \\
\hline $11-20$ & 0.240 & 0.225 & 0.171 & 0.295 \\
\hline $20-30$ & 0.287 & 0.331 & 0.131 & 0.082 \\
\hline $31-40$ & 0.008 & 0.006 & 0.039 & 0.051 \\
\hline $41-50$ & 0.000 & 0.000 & 0.001 & 0.002 \\
\hline$>50$ & 0.000 & 0.000 & 0.002 & 0.002 \\
\hline Unknown & 0.090 & 0.057 & 0.196 & 0.233 \\
\hline \multicolumn{5}{|l|}{ Mother's education } \\
\hline 0-8 years & 0.042 & 0.028 & 0.044 & 0.029 \\
\hline 9-11 years & 0.162 & 0.193 & 0.269 & 0.248 \\
\hline 12 years & 0.465 & 0.420 & 0.415 & 0.392 \\
\hline $13-15$ years & 0.219 & 0.214 & 0.183 & 0.231 \\
\hline$\geq 16$ years & 0.074 & 0.090 & 0.079 & 0.089 \\
\hline Unknown & 0.038 & 0.055 & 0.010 & 0.012 \\
\hline \multicolumn{5}{|l|}{ Mother's age } \\
\hline$<20$ & 0.117 & 0.178 & 0.156 & 0.192 \\
\hline $20-29$ & 0.669 & 0.511 & 0.577 & 0.585 \\
\hline$\geq 30$ & 0.213 & 0.312 & 0.267 & 0.223 \\
\hline \multicolumn{5}{|l|}{ Insurance coverage } \\
\hline Medicaid & 0.502 & 0.438 & 0.569 & 0.539 \\
\hline Other public & 0.046 & 0.016 & 0.021 & 0.020 \\
\hline Private & 0.372 & 0.467 & 0.316 & 0.380 \\
\hline Uninsured & 0.077 & 0.076 & 0.081 & 0.054 \\
\hline Insurance unknown & 0.003 & 0.004 & 0.013 & 0.008 \\
\hline First birth (yes=1) & 0.435 & 0.456 & 0.430 & 0.436 \\
\hline \multicolumn{5}{|l|}{ Maternal race } \\
\hline White & 0.887 & 0.874 & 0.873 & 0.869 \\
\hline Black & 0.071 & 0.061 & 0.111 & 0.094 \\
\hline Other & 0.042 & 0.064 & 0.016 & 0.037 \\
\hline Married $($ yes $=1)$ & 0.493 & 0.500 & 0.622 & 0.569 \\
\hline Pregnancy unintended (yes $=1$ ) & 0.501 & 0.512 & 0.501 & 0.516 \\
\hline \multicolumn{5}{|l|}{ Pre-pregnancy smoking } \\
\hline$<11$ & 0.207 & 0.282 & 0.195 & 0.250 \\
\hline
\end{tabular}


11-20

$>20$

Real tax \$ (1982-84)
0.632

0.161

40.375
0.626

0.092

55.452
0.635

0.170

29.135
0.621

0.129

28.532 
Table 3: Changes in Quit Probabilities Before, During and After Pregnancy,

10 PRAMS States, 1993-1999

\begin{tabular}{|c|c|c|c|c|}
\hline & $\begin{array}{c}\text { Quit_ever_before } \\
\text { (1) }\end{array}$ & $\begin{array}{c}\text { Quit_before_during } \\
\text { (2) }\end{array}$ & $\begin{array}{c}\text { Resume } \\
\text { (3) }\end{array}$ & $\begin{array}{c}\text { Quit_before_after } \\
\text { (4) }\end{array}$ \\
\hline $\begin{array}{l}\text { Taxes at various points in time } \\
\text { Real tax at age } 14\end{array}$ & $\begin{array}{l}0.0016 \\
(2.42)^{* *}\end{array}$ & & & \\
\hline Real tax 3 months pre-conception & & $\begin{array}{l}0.0035 \\
(3.13)^{* *}\end{array}$ & & $\begin{array}{l}0.0026 \\
(2.96)^{* *}\end{array}$ \\
\hline Real tax at interview date & & & $\begin{array}{l}-0.0038 * * \\
(2.78)\end{array}$ & \\
\hline $\begin{array}{l}\text { Selected covariates } \\
\text { Unintended pregnancy }\end{array}$ & $\begin{array}{l}-0.065 \\
(4.92)^{* *}\end{array}$ & $\begin{array}{l}0.006 \\
(0.34)\end{array}$ & $\begin{array}{l}-0.009 \\
(0.44)\end{array}$ & $\begin{array}{l}0.005 \\
(0.39)\end{array}$ \\
\hline First birth & $\begin{array}{l}-0.071 \\
(7.13)^{* *}\end{array}$ & $\begin{array}{l}0.144 \\
(9.12)^{* *}\end{array}$ & $\begin{array}{l}-0.106 \\
(6.45)^{* *}\end{array}$ & $\begin{array}{l}0.101 \\
(8.47)^{* *}\end{array}$ \\
\hline 10-20 cigarettes/day pre-pregnancy & & $\begin{array}{l}-0.347 \\
(21.65)^{* *}\end{array}$ & $\begin{array}{l}0.099 \\
(4.13)^{* *}\end{array}$ & $\begin{array}{l}-0.201 \\
(10.60)^{* *}\end{array}$ \\
\hline $21+$ cigarettes/day pre-pregnancy & & $\begin{array}{l}-0.384 \\
(22.39)^{* *}\end{array}$ & $\begin{array}{l}-0.003 \\
(0.09)\end{array}$ & $\begin{array}{l}-0.165 \\
(17.84)^{* *}\end{array}$ \\
\hline $\begin{array}{l}\text { Elasticity } \\
\text { Mean of dependant variable } \\
\text { Observations }\end{array}$ & $\begin{array}{c}0.66 \\
0.30 \\
38099\end{array}$ & $\begin{array}{l}1.04 \\
0.42 \\
27514\end{array}$ & $\begin{array}{c}-1.00 \\
0.51 \\
10927\end{array}$ & $\begin{array}{l}1.46 \\
0.23 \\
27550\end{array}$ \\
\hline
\end{tabular}

All models were estimated as probits. Figures are $\mathrm{d}($ Prob Quit=1)/dtaxes $\mathrm{i}$. T-ratios are in parentheses. Models include indicator variables for family income (5), health insurance (4), education (5), age (2), race (2), marital status (1), plus state and year fixed effects. Resume models also include the time in days between delivery and the postpartum interview. All models are weighted by survey weights and standard errors have been adjusted for clustering by state and year. 
Table 4. Cigarette Taxes Three Months before Delivery and Probability of Quitting Smoking during Pregnancy: Sensitivity to Specification and Sample of PRAMS States

\begin{tabular}{lccc}
\hline & Marginal effect & t-ratio & Price elasticity \\
\hline 1. Full sample (from Table 3) & .0035 & 3.13 & 1.04 \\
2. Only state and year fixed effects & .0028 & 2.64 & 0.84 \\
3. Full sample less Alaska & .0042 & 2.94 & 1.26 \\
4. Full sample less Maine & .0037 & 3.04 & 0.90 \\
5. Full sample less New York & .0032 & 3.05 & 1.14 \\
6. Full sample less Washington & .0039 & 2.30 & 0.55 \\
7. Only Alaska and non-tax changing states & .0020 & 2.92 & 0.63 \\
8. Only Maine and non-tax changing states & .0023 & 0.94 \\
9. Only New York and non-tax changing states & .0110 & 4.48 \\
10. Only Washington and non-tax changing states & .0041 & .0019 & 3.44 \\
11. Only AK, ME, NY and WA & & 1.70 & 1.17 \\
\hline
\end{tabular}

All models were estimated as probits. Marginal effects are the $\mathrm{d}(\mathrm{Quit}=1) / \mathrm{dTax}_{\mathrm{I}}$. Except for row 2, all models include indicator variables for parity (1), pregnancy intentions (1), and pre-pregnancy smoking (2), family income (5), health insurance (4), education (5), age (2), race (2), marital status (1), plus state and year fixed effects. All models are weighted by survey weights and standard errors have been adjusted for clustering by state and year 
Table 5. Cigarette Taxes and Probability of Quitting Smoking during Pregnancy: By Parity, Maternal School and Pre-pregnancy Smoking, 10 PRAMS States 1993-1999

\begin{tabular}{|c|c|c|c|c|c|c|}
\hline & \multicolumn{2}{|c|}{ Parity } & \multicolumn{2}{|c|}{ Maternal Schooling } & \multicolumn{2}{|c|}{ Pre-Pregnancy Smoking } \\
\hline & $\begin{array}{c}\text { First Birth } \\
\text { (1) }\end{array}$ & $\begin{array}{l}\text { Second and } \\
\text { higher order } \\
\text { birth } \\
(2)\end{array}$ & $\begin{array}{c}\text { High school } \\
\text { education or } \\
\text { less } \\
(3)\end{array}$ & $\begin{array}{l}\text { More than } \\
\text { high school } \\
\text { (4) }\end{array}$ & $\begin{array}{l}\text { Less than } 10 \\
\text { cigarettes/day } \\
\text { (5) }\end{array}$ & $\begin{array}{c}10 \text { or more } \\
\text { cigarettes/day } \\
(6)\end{array}$ \\
\hline $\begin{array}{l}\text { Real tax } 3 \text { months before } \\
\text { conception }\end{array}$ & $\begin{array}{c}0.0043 \\
(3.29) * *\end{array}$ & $\begin{array}{l}0.0028 \\
(2.24)^{*}\end{array}$ & $\begin{array}{c}0.0038 \\
(3.28)^{* *}\end{array}$ & $\begin{array}{l}0.0021 \\
(0.94)\end{array}$ & $\begin{array}{l}0.0028 \\
(2.24)\end{array}$ & $\begin{array}{c}0.0032 \\
(2.49) * *\end{array}$ \\
\hline Elasticity & 1.03 & 1.02 & 1.29 & 0.49 & 0.50 & 1.22 \\
\hline Mean Dep var & 0.53 & 0.35 & 0.38 & 0.54 & 0.72 & 0.34 \\
\hline Observations & 12465 & 15049 & 19813 & 7198 & 6385 & 21129 \\
\hline
\end{tabular}

All models were estimated as probits. Figures are $\mathrm{dQ} / \mathrm{dX}$. T-ratios are in parentheses. Models include indicator variables for family income (5), health insurance (4), education (5), age (2), race (2), marital status (1), parity (1), pregnancy intentions (1), pregnancy smoking (2) and state and year fixed effects. All models are weighted by survey weights and standard errors have been adjusted for clustering by state and year. 
FIGURE 1: Smoking During Pregnancy, BRFSS, PRAMS and Birth Certificates

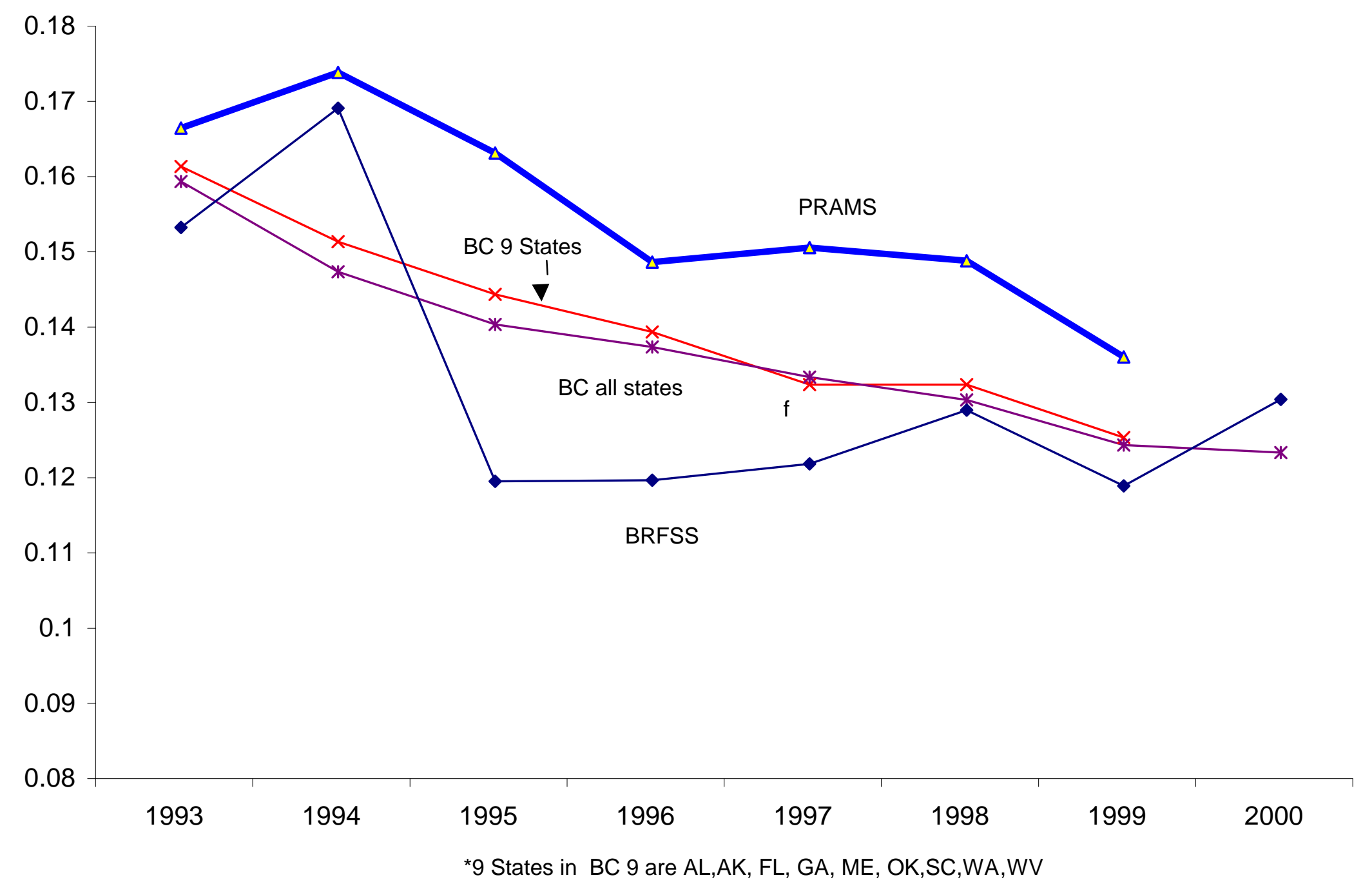


Figure 2: Quit rates Three Months Before Pregnancy among Ever Smokers: Tax Changing vs. Non-Tax Change States in PRAMS*

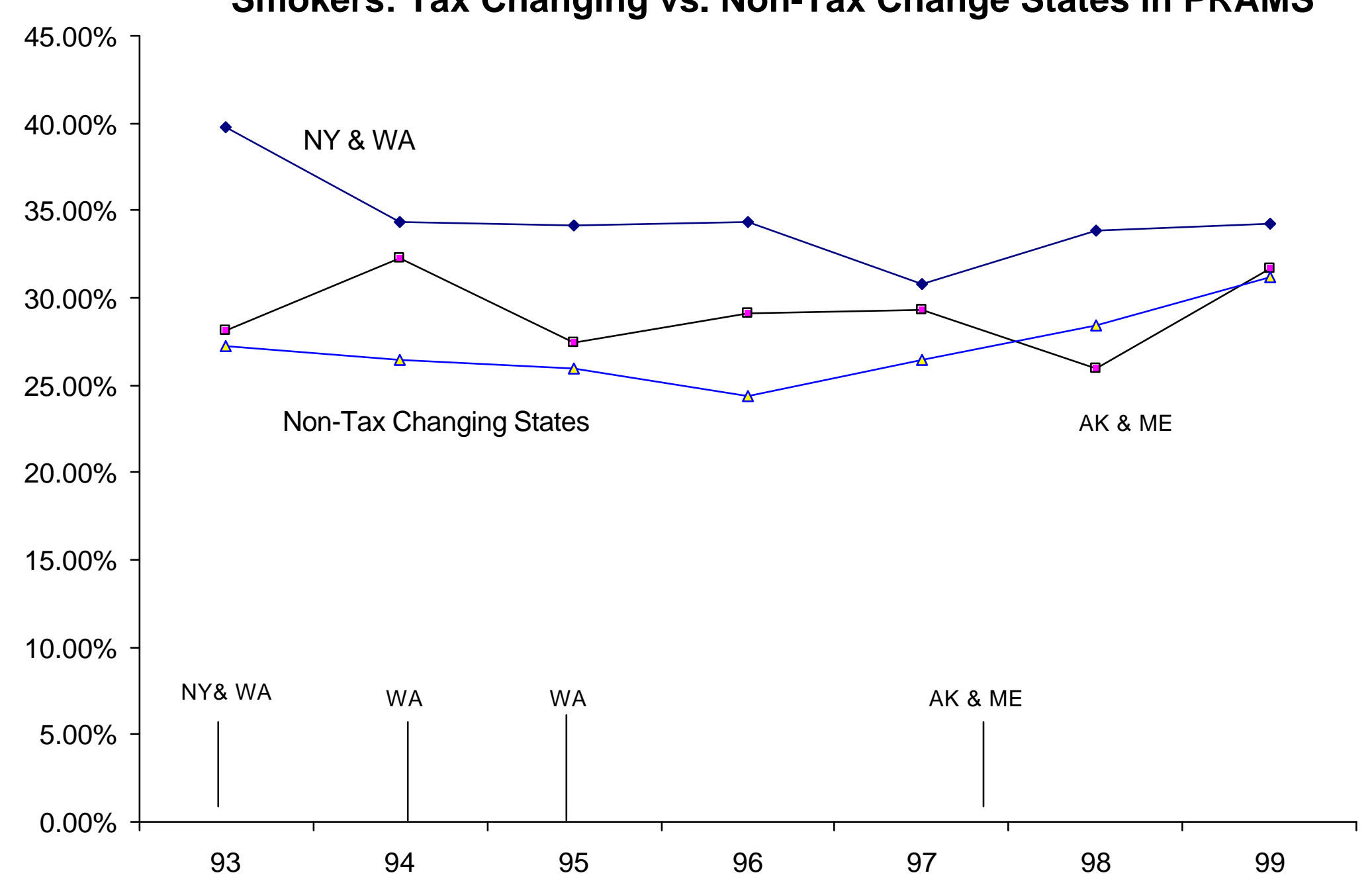

${ }^{*}$ Tax Changes NY 39-56 6/1/93: WA 34-54 7/1/93, 54-56.5 7/1/94 56.5-81.5 7/1/95: AK 29-100 10/1/97: ME 37-74 11/1/97 
Figure 3: Quit rates During Pregnancy among Women that Smoked Three Months Before Pregnancy: Tax Changing vs. Non-Tax Change States in PRAMS*

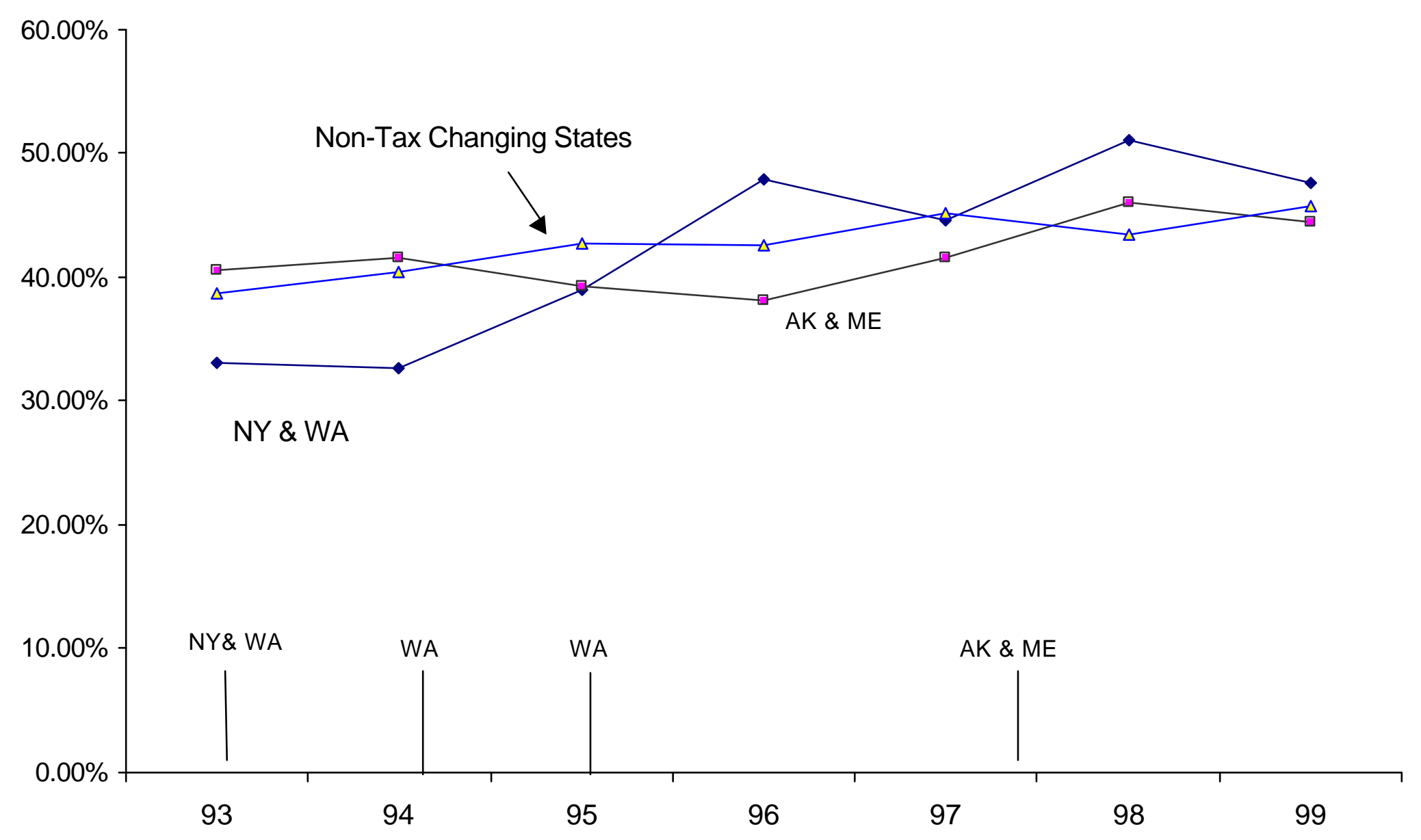

*Tax Changes NY 39-56 6/1/93: WA 34-54 7/1/93, 54-56.5 7/1/94 56.5-81.5 7/1/95: AK 29-100 10/1/97: ME 37-74 11/1/97 
Figure 4: Postpartum Relapse Rates among Women that Quit during Pregnancy: Tax Changing vs. Non-Tax Change States in PRAMS*

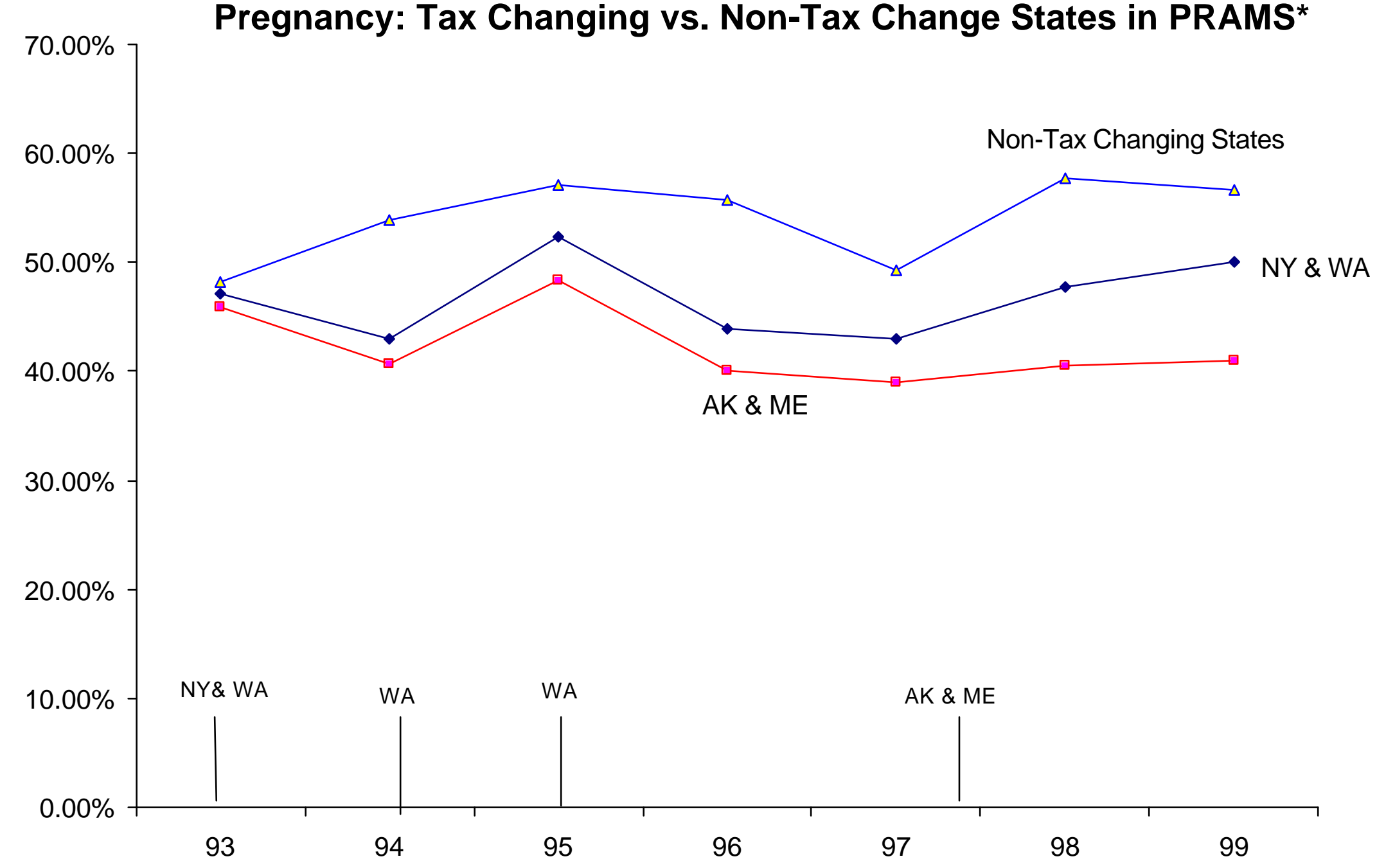

*Tax Changes NY $39-56$ 6/1/93: WA 34-54 7/1/93, 54-56.5 7/1/94 56.5-81.5 7/1/95: AK 29-100 10/1/97: ME 37-74 11/1/97 
Figure 5: Quit rates from Three Months Before Pregnancy to Postpartum : Tax Changing vs. Non-Tax Change States in PRAMS*

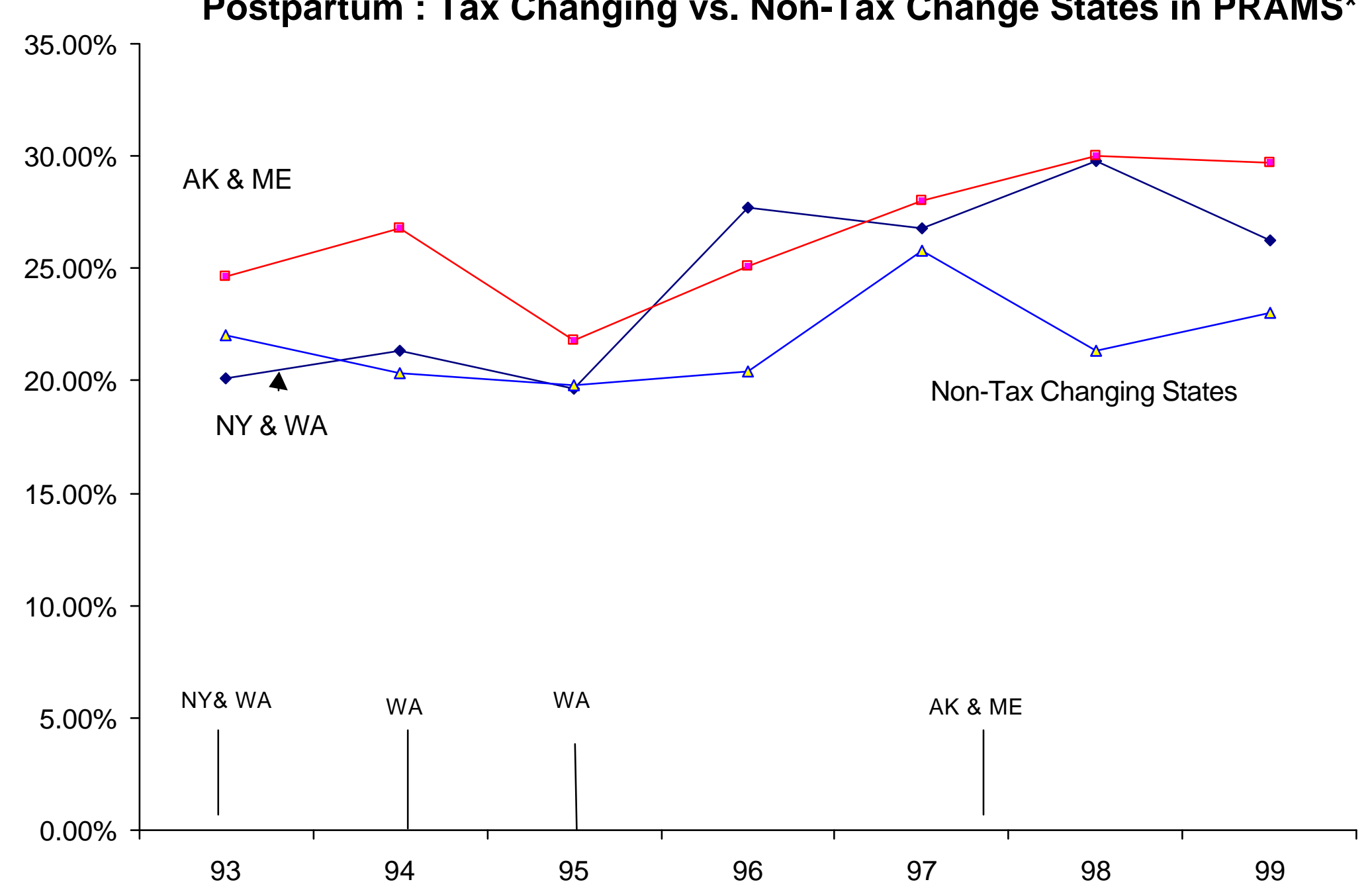

${ }^{*}$ Tax Changes NY 39-56 6/1/93: WA $34-54$ 7/1/93, 54-56.5 7/1/94 56.5-81.5 7/1/95: AK 29-100 10/1/97: ME 37-74 11/1/97 